\title{
CAPOEIRA E CORPO NA INTERFACE COM A TECNOLOGIA: A PRODUÇÃO DO CONHECIMENTO EM DISSERTAÇÕES E TESES NO BRASIL
}

\section{Paulo Rogerio Barbosa do Nascimento iD ${ }^{1}$}

Resumo: Este artigo visa identificar estudos das áreas de conhecimento da Educação Física e de outras que tratam dos temas capoeira, corpo e tecnologias, publicados no período de 2009 a 2019. Trata-se de pesquisa bibliográfica/documental do tipo levantamento de produção de conhecimentos a partir de descritores específicos da base de dados da Capes e da Biblioteca Digital Brasileira de Teses e Dissertações. Apesar de limitados, os estudos encontrados demonstram interação da capoeira com a tecnologia de forma a malear aspectos tradicionais dessa arte cultural popular, que vão se transformando e ganhando visibilidade no mundo, contribuindo para a expansão e ressignificação das suas técnicas e rituais. A tecnologia permitiu a relação da capoeira com a tradição e com o corpo, garantindo espaço mundial a partir do aprendizado e da comunicação, formando redes de praticantes com diferentes configurações.

Palavras-chave: Capoeira; Corpo; Tecnologias; Cultura popular.

\section{CAPOEIRA AND BODY INTERFACED WITH TECHNOLOGY: KNOWLEDGE PRODUCTION IN THESIS AND DISSERTATIONS IN BRAZIL}

Abstract: This article aims to identify studies in the field of Physical Education and related areas that address the themes "capoeira, body and technologies", published between 2009 and 2019. This is a bibliographical/documental literature review that gathers studies on the topic through selected keywords from the Capes database and the Brazilian Digital Library of Thesis and Dissertations. Although limited, the studies found that the interaction between capoeira and technology molds traditional aspects of this popular culture and transforms it, allowing capoeira to spread around the world with new and resignified techniques and rituals. Technology has encouraged the relationship of capoeira with the tradition and the body to earn its space through learning and communication by forming networks of practitioners of different backgrounds.

Keywords: Capoeira; Body; Technologies; Popular culture.

\section{Introdução}

\footnotetext{
${ }^{1}$ Mestre em Educação nas Ciências pela Universidade Regional do Noroeste do Estado do Rio Grande do Sul (Unijuí), Ijuí- RS. Professor Assistente do Curso de Licenciatura em Educação Física da Universidade Regional do Cariri (URCA), Crato/CE. E-mail: paulorogerio.nascimento@urca.br.
} 
A capoeira, atualmente, é uma das expressões culturais brasileiras mais difundidas no mundo, cuja prática nasceu da diáspora africana, constituída ao longo dos séculos como um saber corporal do tipo arquivo-arma (TAVARES, 2012). Nesse cenário, o corpo e o seu uso pragmático enquanto instrumento de luta têm lugar e, ao mesmo tempo, trazem consigo marcas simbólicas, formando um arcabouço cultural identitário.

No século XIX, no Rio de Janeiro, a capoeira se caracterizava por meio das Maltas - grupos que se rivalizavam, dialogavam e ou conflitavam no campo da política local, promovendo arruaças. Esses grupos tinham modos específicos de se vestir, assim como códigos peculiares de comunicação, e formavam um espaço de propagação dos ensinamentos da capoeira e da educação do corpo (SOARES, 2004).

Pires (2001), ao investigar a capoeira da segunda metade do século XIX, em Salvador, baseado em Manuel Querino, aponta similaridades com a capoeira carioca, especialmente quanto a disputas espaciais nas ruas e bairros. $O$ autor ressalta o que foi testemunhado e passou a fazer parte do imaginário social, como a ludicidade, os instrumentos, o canto, a intensa e peculiar movimentação corporal, o uso da navalha e do cacete como arma. Contesta, por outro lado, a visão social da capoeira "vagabundo", relativizando as generalizações e mostrando, por intermédio de documentações, as diversas ocupações que esses exerciam.

Na primeira metade do século XX, a capoeira começou a ganhar estrutura de escola, de grupo, alinhada a um modelo esportivizado ${ }^{2}$, cujo ensino passou a ser inaugurado em academias ${ }^{3}$, sendo projetada a um contexto social amplo, onde atraiu praticantes de classes sociais mais abastadas. Manuel dos Reis Machado (Mestre Bimba) foi um dos responsáveis por coadunar a capoeira ao espírito cívico e nacionalista da época, criando a Luta Regional Baiana, que Ihe conferiu um método de ensino conformado a uma tendência de ênfase técnica, uniformidade e eficiência 4 . Vieira (1996) compreendeu tais elementos como de disciplinamento do corpo dialogando com o espírito militar de conformação corporal, fruto do momento sociopolítico que o Brasil vivia na era Vargas.

Em paralelo a Manuel dos Reis Machado (Mestre Bimba), outros capoeiristas seguiam praticando a sua capoeira das ruas, porém, aos poucos começaram a se organizar, constituindo a "Capoeira de Angola", cujo representante maior foi Vicente Ferreira Pastinha (Mestre Pastinha). Em torno dele reuniram-se diversos capoeiristas, que também contaram com o apoio de intelectuais vinculados a ideais identitários do povo brasileiro, do qual a capoeira faria parte. A Capoeira Angola se desenvolveu ressaltando a ludicidade, a ancestralidade e a ritualização, ao mesmo tempo em que inseriu elementos esportivos, como a figura do Juiz de Campo 5 (PIRES, 2001).

\footnotetext{
${ }^{2}$ A capoeira passou a ter uma metodologia de ensino, uniformização e graduação - elementos do campo esportivo.

3 Mestre Bimba foi o responsável por inaugurar o ensino da capoeira com método em um espaço fechado, denominado "academia", sendo que até então ela estava vinculada às ruas.

${ }^{4}$ Pires (2001) expressa a questão como sendo uma resposta de Mestre Bimba às vivências em meio à repressão, à capoeira e à marginalidade.

5 Juiz de campo foi uma prática que não perdurou na capoeira popular não esportivizada.
} 
Na segunda metade do século $X X$, a capoeira se destacou como atração folclórica e passou a ser atração em shows e eventos no Brasil e no Exterior. Sua expansão territorial e de adeptos, porém, ocorreu com a formação de inúmeros grupos de capoeira que foram surgindo no Brasil e que, mais tarde, foram migrando com suas filiais para o Exterior ${ }^{6}$.

Nos últimos 80 anos, a capoeira passou de uma atividade criminalizada, de âmbito local para uma atração mundial; de pouca visibilidade e integração entre grupos de diferentes estilos para muitos intercâmbios; de uma transmissão essencialmente oral dos seus fundamentos ${ }^{7}$ para as linguagens das tecnologias de comunicação; da referência local de movimentos, técnicas e trejeitos de corpo para uma diversidade de formas de comportamento técnico e tático no jogo, na roda de capoeira, influenciada pelos diferentes estilos de prática.

Percebe-se, hoje, que as "maneiras" de fazer do corpo na capoeira foram ressignificadas de forma veloz entre os seus praticantes. Ademais, sua lógica de transmissão foi modificada, diminuindo a transmissão oral, presencial e prática do conhecimento pelo mestre de capoeira para uma circulação massiva desses conhecimentos no âmbito virtual, numa diversidade de imagens e textos. Tudo isso compõe uma das linguagens e falas da capoeira nos meios tecnológicos contemporâneos.

É possível afirmar que, "[...] hoje podemos pensar em uma comunidade que se transladou para os novos meios de comunicação, que se fazem entre a escrita e a voz." É dessa maneira que o aprendizado tradicional se altera, pois o Mestre de capoeira já não é o único a dar a lição, e a sua oralidade não é a forma única e mais imediata de acessar o conhecimento, pois "[...] houve uma dilatação dos sentidos, a audição dividindo espaço com a visão, mais presente atualmente $[. .$.$] a rede narrativa que se tece agora se dá também na dimensão$ virtual." Multiplicam-se, assim, os cursos, eventos e tutoriais que ensinam por meio virtual, projetando-se formas de jogar, de ser corpo "[...], na roda de capoeira de uma maneira muito veloz e influente." (EWALD, 2008, p. 7).

Segundo Giroux; Maclaren (1995), a Pedagogia está presente em diversos espaços sociais de produção de conhecimento - ou seja, onde é possível viver e significar a experiência e construir assertivas sobre a vida e todas as coisas que cercam o indivíduo - pode-se falar de pedagogias. Para Costa; Andrade (2015, p. 845), esses espaços diversificados e "artefatos culturais estão hoje implicados tanto nas formas como as pessoas pensam e agem sobre si mesmas e sobre o mundo que as cerca como nas escolhas que fazem e nas maneiras como organizam suas vidas."

A capoeira como espaço pode ser identificada num lugar onde opera uma pedagogia cultural, uma forma particular de conceber o corpo, a técnica, a história e as relações entre as pessoas. Para Silva (2000, p. 89), a pedagogia cultural pode ser entendida como "qualquer instituição ou dispositivo cultural,

\footnotetext{
${ }^{6} \mathrm{Na}$ década de 1970 iniciou a migração de capoeiristas brasileiros que consolidaram seus grupos na Europa e, posteriormente, em outros países.

7 O conceito de "fundamentos" na capoeira extrapola a lógica da técnica e se refere à compreensão dos códigos socioculturais que estruturam a atividade.
} 
que tal como a escola, esteja envolvida - em conexão com relações de poder no processo de transmissão de atitudes e valores [...]."

Sobreira et al. (2016, p. 74) afirmam que na atualidade a tecnologia tem "diminuído as distâncias" entre as pessoas, ao mesmo tempo que tem distanciado "relações corporais próximas, minimizando os contatos, os olhares, os toques, elementos estes característicos da relação humana de qualidade." Novaes (2018) descreve as selfs como uma possibilidade de desenvolver patologização, mas, também, podem ser entendidas como um espetáculo da intimidade, uma forma de se mostrar em desempenho na capoeira, por exemplo (prática muito comum). Trata-se de uma característica do que se chama PósModernidade, onde tudo pode estar na vitrine, contudo, também volátil, diferente das características da Modernidade, com seu espírito de organização e permanência.

Grandes rodas de capoeira são postadas na rede virtual, significadas/mostradas de várias maneiras, como fotografias, selfs, vídeos e discussões/opiniões. O que antes era do universo íntimo dos grupos, agora é popularizado, posto em evidência de maneira rápida. De certa forma, isso tem o poder de acirrar uma competição desenfreada sobre quem aparece mais e sobre quem consegue vender a capoeira ancestral, autêntica, internacionalizada etc.

O efeito da pandemia da Covid-19 potencializou ainda mais as conexões e o tempo de uso e permanência da capoeira no mundo virtual, já que o ambiente físico diminuiu, tornando-se, para muitos, a própria casa. As relações entre professores e alunos, empresários e funcionários, médicos e pacientes, reuniões e tudo o que foi possível, tem sido enquadrado na realidade virtual. De repente, as lives se multiplicaram vertiginosamente e a sensação foi de que todo mundo tinha algo a dizer sobre quase tudo. O jogador de capoeira, um corpo ativo e relacional, precisou se ajustar ao isolamento social e ao avultamento da pedagogia virtual, buscando conhecimentos, compartilhando conhecimentos e ou produzindo conteúdo.

O Programa na Identidade da Capoeira constitui-se de lives com entrevistas (o primeiro a ser transmitido utilizando o Facebook). O objetivo era entrevistar Mestres e estudiosos da arte da capoeira, valorizando o seu saber ancestral, dando-Ihes visibilidade, assim como Mestres novos e ou acadêmicos que pesquisam sobre a capoeira. No período de 01 de abril de 2020 até 14 de março de 2021 - momento de finalização deste artigo - já haviam sido feitas 200 lives/entrevistas, cobrindo todo o período de pandemia do coronavírus, que até esta data ainda não tem solução no Brasil| ${ }^{8}$.

A circulação de conhecimentos e diversidades da tradição oral em relação à capoeira foi desvelada de maneira muito dinâmica pelo mundo. O corpo que, na capoeira, fala pelo gestual, foi obrigado a privilegiar a linguagem verbal mediada pela tecnologia, tendo como assistentes pessoas muito distantes. A

\footnotetext{
8 Estas informações foram concedidas oralmente pelos idealizadores do programa "Na identidade do capoeira", que são Gabriel Nunes Lopes (Contramestre Fly, do Grupo de Capoeira Mandinga), e Edison Coelho (Mestre Dunga, do Grupo de Capoeira Lenço de Seda). Segundo informações desses idealizadores, até a finalização deste artigo o programa já atingia 70 países.
} 
forma como ocorreu a experiência dessa iniciativa e das lives/entrevistas com a análise dos seus conteúdos é algo que ainda está por ser realizada.

Os grupos de capoeira, herdeiros de características da Modernidade, se organizaram de maneira fechada, como a evitar que seus "segredos" fossem mostrados a outros grupos de capoeira, criando, assim, um discurso intragrupo de ser o melhor, o mais original. Contemporaneamente, esta postura foi abalada, pois o grupo e as pessoas estão em toda parte, desnudadas (vamos dizer assim) aos olhares de milhares de pessoas. Depreende-se, com isso, que há um espaço virtual que impôs, inclusive, uma nova estética da capoeira.

O fenômeno da capoeira direciona-se cada vez mais a "[...] uma atitude, uma apropriação, vitalista, hedonista, tribal e presenteísta da tecnologia." (LEMOS, 2002, p. 20). Toda esta dinamicidade colocada ao corpo e à capoeira, atravessada pela tecnologia, modificada e produzido por ela, levou a questionar: Como a comunidade acadêmica tem dialogado com o fenômeno da capoeira na interface com o corpo e a tecnologia, considerando produções científicas do ano de 2009 até o ano de 2019?

O objetivo deste estudo foi identificar e caracterizar pesquisas da área de conhecimento da Educação Física e de outras que tratam do tema: "capoeira, corpo e tecnologias". Procurou-se, assim, compreender as diferentes narrativas, assertivas, regularidades e ou lacunas que têm constituído o campo de pesquisa nesta temática.

A realização deste estudo se justifica pela contemporaneidade do tema e pela necessidade de, na condição de pesquisadores, encontrar no quantitativo dessas produções e nas áreas de interesse dessas pesquisas, temas específicos que têm sido contemplados, podendo, inclusive, pontuar lacunas que sirvam para futuros investimentos em pesquisas.

\section{Metodologia}

Este artigo possui natureza qualitativa, do tipo descritivo e analítico, com delineamento documental e de levantamento de produção do conhecimento. Conforme Gil (2002), esta definição metodológica visa: identificar, descrever e correlacionar variáveis. No caso deste estudo, produzindo um panorama do estado da produção de conhecimento, relativo à correlação entre capoeira/ corpo e tecnologias. Para o desenvolvimento das etapas do percurso metodológico, explicitadas na sequência do texto, referenciou-se em Romanowski e Ens (2006).

Os documentos pesquisados foram dissertações de mestrado e teses de doutorado identificados no catálogo de dissertações e teses da Capes e na Biblioteca Digital Brasileira de Teses e Dissertações, produzidas entre os anos de 2009 e 2019.

Os critérios de inclusão foram a publicação entre os anos 2009 e 2019 e o foco no tema "capoeira, corpo e tecnologia". Como critério de exclusão considerou-se as pesquisas que relacionavam somente parte do tema, ou seja, que apontavam somente "capoeira e corpo" ou "capoeira e tecnologia", não fazendo a intersecção entre os três conceitos. 
Os descritores de busca foram: "capoeira" AND "corpo" AND "tecnologia"; "capoeira" AND "corpo"; "capoeira" AND "tecnologia"; "capoeira" AND "mídia"; "capoeira" AND "internet"; "capoeira" AND "comunicação". Entende-se que essa combinação binária dos termos de busca facilitou a identificação dos estudos, apesar de o tema principal (capoeira, corpo e tecnologia) não ter resultado em muitos achados.

Consequentemente, foram identificados 263 estudos entre teses e dissertações, sendo que alguns foram logo descartados por tratarem a capoeira em outro sentido, ou seja, numa conotação de elemento do solo na relação com a produção agrícola. Da mesma forma também foram descartados resultados repetidos. Os estudos foram analisados, levando em consideração título, palavras-chave, resumo, sumário e, quando necessário, realizou-se a leitura da introdução e das considerações finais, além da literatura de referência.

Das 263 pesquisas identificadas, duas que poderiam passar pelas primeiras análises não foram disponibilizadas, oito preencheram os requisitos e foram selecionadas, e 253 foram descartadas, pois muitas relacionavam capoeira e corpo sem, contudo, vinculá-los à tecnologia ou vice-versa.

\section{Resultados e discussões}

Os estudos foram primeiramente sistematizados numa visão geral dos dados, caracterizando aqueles identificados entre os anos 2009 e 2019. Após apresentá-los, descreveu-se e analisou-se as particularidades dos estudos que apontavam regularidades e ou tendências quanto aos feitos e ditos nas pesquisas relativas à capoeira, corpo e tecnologia.

\section{Quadro 1 - Publicações identificadas no catálogo de teses e dissertações da Capes e na Biblioteca Digital de Brasileira de Teses e Dissertações.}

\begin{tabular}{|l|l|l|l|}
\hline \multicolumn{1}{|c|}{ Título da Pesquisa } & Autor e data & $\begin{array}{l}\text { Titulação/Ár } \\
\text { ea de } \\
\text { Conheciment } \\
\text { o }\end{array}$ & Universidade \\
\hline $\begin{array}{l}\text { Ritomídia: do } \\
\text { ritualístico ao midiático. } \\
\text { A mediatização das } \\
\text { culturas populares de } \\
\text { raiz de matriz africana } \\
\text { na perspectiva da } \\
\text { Capoeira Angola }\end{array}$ & $\begin{array}{l}\text { ABREU, C.C.N. } \\
(2012)\end{array}$ & $\begin{array}{l}\text { Mestre em } \\
\text { Comunicação } \\
\text { Social }\end{array}$ & $\begin{array}{l}\text { Pontifícia } \\
\text { Universidade } \\
\text { Católica de } \\
\text { Minas Gerais - } \\
\text { PUC }\end{array}$ \\
\hline $\begin{array}{l}\text { A roda em rede: as } \\
\text { transformações } \\
\text { culturais da capoeira } \\
\text { nos ambientes } \\
\text { midiáticos digitais }\end{array}$ & MARCHESI, & $\begin{array}{l}\text { Mestre em } \\
\text { Ciências da } \\
\text { Comunicação }\end{array}$ & $\begin{array}{l}\text { Universidade de } \\
\text { São Paulo - USP }\end{array}$ \\
\hline $\begin{array}{l}\text { O ensino da capoeira no no } \\
\text { ensino escolar: blog } \\
\text { como apoio pedagógico }\end{array}$ & $\begin{array}{l}\text { SILVA, L.M.F. } \\
(2012)\end{array}$ & $\begin{array}{l}\text { Mestra em } \\
\text { Desenvolvimen }\end{array}$ & $\begin{array}{l}\text { Universidade } \\
\text { Estadual } \\
\text { Paulista Júlio de }\end{array}$ \\
\hline
\end{tabular}




\begin{tabular}{|c|c|c|c|}
\hline & & $\begin{array}{l}\text { to Humano e } \\
\text { Tecnologias }\end{array}$ & $\begin{array}{l}\text { Mesquita } \mathrm{F}^{\circ}- \\
\text { UNESP, Rio } \\
\text { Claro }\end{array}$ \\
\hline $\begin{array}{l}\text { O dispositivo da } \\
\text { capoeiragem: escritas, } \\
\text { técnicas e estéticas da } \\
\text { existência }\end{array}$ & $\begin{array}{l}\text { FERREIRA, } \\
\text { B.S. } \\
(2013)\end{array}$ & $\begin{array}{l}\text { Mestre em } \\
\text { Comunicação }\end{array}$ & $\begin{array}{l}\text { Universidade } \\
\text { Federal do Rio } \\
\text { de Janeiro - } \\
\text { UFRJ }\end{array}$ \\
\hline $\begin{array}{l}\text { Repassando o passado: } \\
\text { produção e divulgação } \\
\text { de saberes na escola de } \\
\text { Capoeira Angola } \\
\text { Resistência. }\end{array}$ & $\begin{array}{l}\text { SILVA, D.A. } \\
(2013)\end{array}$ & $\begin{array}{l}\text { Mestre em } \\
\text { Divulgação } \\
\text { Científica e } \\
\text { Cultural }\end{array}$ & $\begin{array}{l}\text { Universidade } \\
\text { Estadual de } \\
\text { Campinas - } \\
\text { Unicamp }\end{array}$ \\
\hline $\begin{array}{l}\text { A reinvenção dos } \\
\text { arquivos da capoeira: } \\
\text { uma arqueologia } \\
\text { audiovisual e biopolítica }\end{array}$ & $\begin{array}{l}\text { FERREIRA, } \\
\text { B.S. } \\
(2016)\end{array}$ & $\begin{array}{l}\text { Doutor em } \\
\text { Comunicação }\end{array}$ & $\begin{array}{l}\text { Universidade } \\
\text { Federal do Rio } \\
\text { de Janeiro - } \\
\text { UFRJ }\end{array}$ \\
\hline $\begin{array}{l}\text { Capoeiragem e } \\
\text { tecnologias: } \\
\text { possibilidades culturais }\end{array}$ & $\begin{array}{l}\text { SENA, A.B.D. } \\
(2018)\end{array}$ & $\begin{array}{l}\text { Mestre em } \\
\text { Desenvolvimen } \\
\text { to Humano e } \\
\text { Tecnologias }\end{array}$ & $\begin{array}{l}\text { Universidade } \\
\text { Estadual } \\
\text { Paulista Júlio de } \\
\text { Mesquita F - } \\
\text { UNESP, Rio } \\
\text { Claro }\end{array}$ \\
\hline $\begin{array}{l}\text { Sou capoeira: a } \\
\text { construção de um novo } \\
\text { fazer-se capoeirista } \\
\text { analisado por meios das } \\
\text { gravações de LPs entre } \\
\text { a década de } 1980 \text { a } \\
1990\end{array}$ & $\begin{array}{l}\text { BELFANTE, } \\
\text { D.B. } \\
(2018)\end{array}$ & $\begin{array}{l}\text { Mestre em } \\
\text { História }\end{array}$ & $\begin{array}{l}\text { Universidade } \\
\text { Federal do } \\
\text { Ceará - UFC }\end{array}$ \\
\hline
\end{tabular}

Fonte: dados da pesquisa (2021).

\section{Quadro 2 - Número de pesquisas por ano e distinção entre dissertações e teses.}

\begin{tabular}{|l|l|l|l|l|l|l|l|l|l|l|l|}
\hline Ano & $\begin{array}{l}\mathbf{2 0 0} \\
\mathbf{9}\end{array}$ & $\begin{array}{l}\mathbf{2 0 1} \\
\mathbf{0}\end{array}$ & $\begin{array}{l}\mathbf{2 0 1} \\
\mathbf{1}\end{array}$ & $\begin{array}{l}\mathbf{2 0 1} \\
\mathbf{2}\end{array}$ & $\begin{array}{l}\mathbf{2 0 1} \\
\mathbf{3}\end{array}$ & $\begin{array}{l}\mathbf{2 0 1} \\
\mathbf{4}\end{array}$ & $\begin{array}{l}\mathbf{2 0 1} \\
\mathbf{5}\end{array}$ & $\begin{array}{l}\mathbf{2 0 1} \\
\mathbf{6}\end{array}$ & $\begin{array}{l}\mathbf{2 0 1} \\
\mathbf{7}\end{array}$ & $\begin{array}{l}\mathbf{2 0 1} \\
\mathbf{8}\end{array}$ & $\begin{array}{l}\mathbf{2 0 1} \\
\mathbf{9}\end{array}$ \\
\hline $\begin{array}{l}\text { No de } \\
\text { pesquis } \\
\text { as }\end{array}$ & 0 & 0 & 0 & 3 & 2 & 0 & 0 & 1 & 0 & 2 & 0 \\
\hline $\begin{array}{l}\text { Titulaçã } \\
\text { o }\end{array}$ & 0 & 0 & 0 & $\mathrm{M}(3)$ & $\mathrm{M}(2)$ & 0 & 0 & $\mathrm{D}(1)$ & 0 & $\mathrm{M}(2)$ & 0 \\
\hline
\end{tabular}

Fonte: dados da pesquisa (2021).

Legenda:

D - Dissertação de Mestrado

T - Tese de Doutorado

Percebe-se que dentre os 11 anos pesquisados, o ano de 2012 apresentou três pesquisas; os anos de 2013 e 2018 tiveram duas pesquisas em cada ano; o ano de 2016 teve uma pesquisa; e os anos 2009, 2010, 2011, 2014, 2015, (c) (1) $(9)$ 
2017 e 2019 não tiveram pesquisas, sendo, portanto, sete anos sem publicação na temática.

As pesquisas foram vinculadas a diversas áreas do conhecimento, como Comunicação Social, Ciências da Comunicação, Desenvolvimento Humano e Tecnológico, Comunicação (quatro pesquisas), Divulgação Científica e Cultural, Desenvolvimento Humano e Tecnologias, e História. Foram publicadas oito dissertações de mestrado e uma tese de doutorado. Chamou a atenção o fato de não haver pesquisas com a temática na área de Educação Física, o que consiste em uma lacuna, pois capoeira, corpo e mídia, ainda que separadamente, são assuntos presentes no currículo de formação em Educação Física e no universo da Cultura Corporal de Movimento. Ademais, contemporaneamente, há uma necessidade de melhor compreensão do fenômeno. Trata-se, portanto, de uma lacuna da área para futuras pesquisas.

\section{Quadro 3 - Número de pesquisas realizadas por universidades (2009 a 2019).}

\begin{tabular}{|l|c|c|}
\hline \multicolumn{1}{|c|}{ Universidades } & $\begin{array}{c}\text { Regiões } \\
\text { do País }\end{array}$ & $\begin{array}{c}\text { No de } \\
\text { Estudos }\end{array}$ \\
\hline $\begin{array}{l}\text { Universidade Estadual Paulista Júlio de Mesquita } \\
\text { Filho - } \\
\text { UNESP, Rio Claro }\end{array}$ & SE & 2 \\
\hline Universidade Federal do Rio de Janeiro - UFRJ & SE & 2 \\
\hline Universidade de São Paulo - USP & SE & 1 \\
\hline Universidade Estadual de Campinas - Unicamp & SE & 1 \\
\hline Universidade Federal do Ceará - UFC & NE & 1 \\
\hline $\begin{array}{l}\text { Pontifícia Universidade Católica de Minas Gerais } \\
\text { - PUC/MG }\end{array}$ & SE & 1 \\
\hline
\end{tabular}

Fonte: dados da pesquisa (2021).

As pesquisas ficaram distribuídas entre seis universidades, sendo que apenas duas tiveram duas pesquisas cada uma, o que demonstra que ainda não há um espaço consolidado de pesquisa em relação à temática. Ao se considerar o número de pesquisas por região do país, percebe-se que a Região Sudeste (SE) se destacou com sete estudos provindos de cinco universidades, enquanto a Região Nordeste (NE) apresentou um trabalho em apenas uma universidade. As demais regiões do País não apresentaram produções.

Passa-se, então, a descrever e analisar as pesquisas identificadas, demarcando as suas contribuições para este estudo e fazendo a interlocução entre as pesquisas e as literaturas das áreas afins ao tema.

Abreu (2012, p. 141) investigou o processo de midiatização da Capoeira Angola e a "ressignificação simbólica das culturas de raiz de matriz africana em Belo Horizonte". A proposta da pesquisa foi relacionar uma cultura de ordem presencial como a capoeira e a sua propagação por meio de estratégias virtuais. O autor verificou a presença do processo de midiatização do grupo de capoeira pesquisado, especialmente no caso de blogs mantidos pelo grupo nas suas 17 filiais, cujo espaço transmite informações sobre eventos e rodas de capoeira, vídeos e textos, além da articulação de políticas de reconstrução simbólica. 
Segundo Abreu (2012), a estratégia virtual de transmissão dos aspectos tradicionais é efetiva e contribui para criar e manter os aspectos simbólicos da capoeira, sendo as categorias analíticas denominadas "marcadores da tradição", todas identificadas nos conteúdos virtuais. Dessa forma, o grupo de capoeira que provém de uma tradição oral vai aos poucos se inserindo nas possibilidades tecnológicas, expandindo os seus fazeres e cativando novos praticantes. Podese afirmar, então, que os discursos contidos em pequenas comunidades alcançam um número maior de pessoas que não são propriamente da comunidade da capoeira, mas que podem vir a aderir.

Há indicativo de uso das mídias com fim publicitário, porém, conforme Abreu (2012), o espaço é subutilizado, uma vez que os espaços de aula, as rodas de capoeira e os eventos nem sempre estão atualizados enquanto informação. $\mathrm{O}$ uso das mídias tem aumentado e tem sido um forte instrumento de vínculo com o público externo, demonstrando que é possível manter e divulgar aspectos da tradição no meio midiático sem prejuízo do aspecto presencial da capoeira.

Silva (2013), em sua pesquisa, percebeu que a tradicionalidade defendida no campo político e pedagógico do grupo de Capoeira Angola ainda é baseada na oralidade, tendo o Mestre como referência. Mantém-se, portanto, um ensino no âmbito do comunitário, com referências próprias que legitimam o grupo de capoeira e seus praticantes. Há, porém, uma circulação de saberes que, de certa forma, se interconectam, flexibilizando discursos unívocos sobre a capoeira. Isto acontece porque os praticantes têm a oportunidade de interagir mais com a Tecnologia da Informação e com outros grupos amigos. Assim, a cultura da capoeira não é estática, mesmo nos meios mais tradicionais, pois a dinâmica da informação e a necessidade da reinvenção de tradições se colocam de maneira imperativa.

A pesquisa de Ferreira (2013) compactua com a de Silva (2013) ao analisar o processo histórico de divulgação dos conhecimentos da capoeira que, no seu início, devido a seus praticantes serem iletrados e a prática proibida, ficava mais no âmbito da oralidade, do segredo, do difuso. No entendimento do autor, na atualidade, a capoeira é como um dispositivo, o que significa que os enunciados sobre a capoeira circulam nos meios tecnológicos, como se fosse uma grande roda virtual na qual os discursos se encontram e se desencontram, igualando-se às práticas dos sujeitos, as quais são influenciadas em termos de conhecimentos históricos, técnicos e ritualísticos.

Antigos registros da capoeira fazem referência à atividade como "crime", sem nunca os contextualizar. Aos poucos, contudo, surgiram publicações prescritivas que enfatizavam o autoaprendizado da capoeira, comparando-a a outras lutas e ressaltando a sua nacionalidade. O registro escrito dos conhecimentos sobre a capoeira deu um novo status ao praticante/autor, sendo uma característica a não referência a elementos ritualísticos e ou musicais que porventura estabeleceriam ligações com as raízes étnicas da capoeira. Isto recebeu críticas como a ideia de "branqueamento" da capoeira (FRIGÉRIO, 1989).

A identificação da capoeira com o modelo esportivo europeu também perpassou essas publicações, configurando uma espécie de manipulação à livre circulação social desses conhecimentos provindos da cultura popular sob a ótica 
da luta asséptica de seus códigos culturais em conjunto com os exercícios físicos. Os aspectos filosóficos e socioculturais da capoeira foram abordados mais para o final do século XX com as obras de Mestre Nestor Capoeira (1992, 1995 e 2019).

As produções escritas foram como portas às produções audiovisuais e passaram a retratar a capoeira no seu contexto popular de prática, com temática sociocultural, bem como luta coadjuvante em filmes do mercado do entretenimento. A gravação de discos fonográficos com conteúdo da capoeira foi outro artifício que contribuiu para a sua sistematização e divulgação, a exemplo do disco fonográfico gravado por Mestre Bimba, que era um complemento do seu curso de capoeira e da sua metodologia de ensino.

"As tecnologias ajudaram, em parte, a preservar os ditos dos velhos mestres e suas experiências de vida, trazendo para a atualidade certas imagens de um passado que vinha moldando a experiência brasileira moderna" (FERREIRA, 2013, p. 121). É a autenticação de narrativas e metodologias de vida em comunidade e ensino do capoeirista, ou seja, um recurso didático, em que "[...] novas camadas de oralidade e memória estabelecendo ainda uma estética da capoeiragem integrada com a tecnologia do áudio." (p. 126).

Esta nova estética se manifestou na aproximação dos capoeiristas da maneira de cantar de um ou outro Mestre de capoeira, ou da apropriação dos discursos falados e cantados nos discos fonográficos que, posteriormente, foram para os CDs e outros dispositivos mais modernos, que já apresentavam o vídeo gravado com anterioridade ou mesmo em tempo real.

A apropriação dos capoeiristas também passou a ser gestual/corporal no sentido de uma estética que circula e começa a ser mais valorizada, gerando certo desconforto para antigos Mestres de capoeira que não gostariam de ver os seus estilos contaminados por outras influências de fazer (no gestual e ritual) da capoeira, o que se revelou um caminho sem volta. Outro fenômeno são os Mestres e pseudomestres de capoeira que têm na rede de Internet, um arsenal de possibilidades para ampliar ou se apropriar de gestuais e rituais que circulam livremente no universo virtual da capoeira9.

Marchesi (2012, p. 343) pesquisou sobre a "influência da mídia digital nos processos de reprodução e transformação de culturas tradicionais contemporâneas, tendo como foco a capoeira". O autor pontua os atores-redes como protagonistas desse processo ao criarem "narrativas, vontades, conexões e interações tecno-humanas." Todas essas interações subjetivam o sujeito e significam o seu corpo, a exemplo de alguns grupos de capoeira que se identificam pelo visual do cabelo e de suas vestimentas, mostrando que todos são diferentes, mas ao mesmo tempo todos são iguais. O corpo humano não é

\footnotetext{
${ }^{9}$ Em conversa com um antigo e reconhecido Mestre de capoeira, este dizia aproveitar as viagens de avião para planejar as movimentações que passaria aos participantes do curso que iria ministrar, fosse no Brasil ou no Exterior. A sensação é de que há necessidade do novo, uma não conformação com a capoeira naquilo que lhe é estruturante, talvez esteja aí uma explicação para a criação ou inserção de novos movimentos no jogo da capoeira e nos seus treinamentos. De certa forma, não deixa de ser um mercado que precisa fazer o seu cliente desejar nova mercadoria, de utilizá-la, descartá-la e inaugurar um novo desejo. Eis mais uma característica da modernidade líquida conceituada por Bauman (2001) ao configurar a capoeira.
} 
um dado natural em si, mas a cultura lhe impõe sentidos e significados (LE BRETON, 2011).

A expansão e a digitalização da capoeira, para Marchesi (2012, p. 345), estão na interdependência de dois processos: "as etnhoscapes - os fluxos migratórios dos capoeiristas - e as mediascapes - os fluxos de imagens e informações da capoeira pelos meios eletrônicos de massa [...]", sendo que as mediascapes podem ter influenciado sobremaneira novas etnhoscapes. A capoeira, por meio das redes digitais e de seus territórios físicos entrelaçados num desenho rizomórfico e ramificado, vai brotando nos mais longínquos locais.

Isso, porém, não uniformiza a capoeira, mas mantém a diversidade numa rede comunicante e consciente das diferenças e semelhanças. De certa maneira, o achado de Marchesi (2012) dialoga com a interpretação dos achados de Ferreira (2013). É possível perceber que a noção de indivíduo na Modernidade já não basta, sendo necessário fazer um tipo, como o corpo e gestual da Capoeira de Angola ou como o da Capoeira Regional. Em outras palavras, o tipo capoeira descolado - transita por ideias e ideais críticos em relação à sociedade, para quem a capoeira é um símbolo de resistência - até o capoeirista competidor - que busca o desempenho em suas atuações e é simpatizante de campeonatos.

Para Marchesi (2012), a intenção de muitos protagonistas da digitalização da capoeira está na intenção de propor e fomentar uma prática para além do seu grupo, desvinculada de bandeira ou de marca. A proliferação dos vídeos de capoeira na Internet estimula o retorno ao passado, quando o aprendizado se dava pela observação, porém, amplia a possibilidade de falar sobre a capoeira, dando visibilidade a outras escolas para além daquela frequentada pelo praticante, além de ampliar consideravelmente as referências e experiências.

A nova geração de capoeiristas, segundo Marchesi (2012, p. 32) encontrase "[...] transcrevendo a cultura de maneira multiforme para os ambientes digitais [...]", o que muitos fazem de forma voluntária, apaixonados pela capoeira e pelo reconhecimento de seus pares. O ambiente digital está se configurando num novo chão para se jogar a capoeira, considerado pela autora como o novo local da cultura. De certa forma, isso quebra certos autoritarismos de Mestres de capoeira que se dizem detentores da cultura capoeirista, uma vez que a capoeira saiu do quintal de casa e se dissipou pelas mídias sociais, ganhando o mundo.

O estudo de Sena (2018, p. 65) investiu na compreensão das "interações entre capoeiristas e as tecnologias da informação e comunicação de modo a enxergar os impactos nas tradições da capoeira, portanto, na produção cultural e na subjetividade dos capoeiristas." Para o autor, há uma rede de interação constituidora de subjetividades entre capoeiristas de diversos grupos, onde trocas intensas sobre conhecimentos da capoeira são veiculadas, cujo intuito maior é colocar a capoeira em evidência no dia a dia. Os objetivos são pessoais, como se informar, aprender uma técnica nova de movimentação, bem como grupais, divulgar o trabalho de seu grupo e angariar praticantes.

Ferreira (2016) investigou a reinvenção dos arquivos da capoeira e fez uma arqueologia audiovisual e biopolítica a respeito, afirmando que, atualmente, a disponibilidade da capoeira se dá em várias portas de saída da informação, e que essas são elaboradas por diferentes fontes e meios, podendo vir da prática, 
do estudo histórico ou da "memória individual ou coletiva." Acrescenta-se, todavia, que a relação do Estado com a capoeira, nas últimas décadas, não deixa de ser uma biopolítica que pode desencadear um processo de esportivização da sua prática, ou mesmo signos e sentidos com os quais a capoeira vem dialogando, ora se aproximando, ora se afastando. A sociedade interpretada como modernidade líquida concede espaços à diversidade, mobilidade, reinvenções e ressignificações, em cujo espaço a capoeira e seus diversos grupos vão se moldando, conforme princípios e ou conveniências (BAUMAN, 2001).

O conceito de Rizoma utilizado pelo autor demonstra que os caminhos da aprendizagem vão se estabelecer e ou inaugurar novos trajetos e cada qual traz de um desses lugares o seu saber. Esta é uma complexa rede de constituições da capoeira, a qual se torna híbrida e heterogênea. Ainda assim é possível identificar traços comuns nas formas de praticar a capoeira, entretanto, uma questão colocada pela Arqueologia é: qual o papel da memória neste processo?

Ferreira (2016) percebe que a noção do Mestre de capoeira se desfaz como atração folclórica a fim de que os outros façam as suas produções de registro sejam antropólogos, sociológicos ou, inclusive, os próprios Mestres que, na Contemporaneidade, começaram a produzir este material. Eis aí uma mudança significativa, pois quem vinha sendo discriminado ao longo da História pode, agora, produzir e reproduzir a sua fala, as suas verdades. Esta é, inclusive, uma mudança de relação com o Estado brasileiro que criminalizou a capoeira por muito tempo, quase jogando-a no ostracismo total na virada do século XIX para o século XX. A vinculação da capoeira com aspectos do esporte e a aproximação do Estado, todavia, deu-Ihe relativa liberdade.

A Capoeira Regional e a Capoeira Angola - duas formas de conceber a capoeira - balizas para praticamente todos os grupos de capoeira na atualidade, surgiram neste momento de aproximação com o Estado como uma espécie de símbolo nacional. A capoeira se desenvolveu e migra para a Europa e o restante do mundo. Em 2008, foi Ihe dado o título de Patrimônio Cultural Brasileiro (IPHAN) e, após, em 2014, o título de Patrimônio Imaterial da Humanidade (Unesco). Esta é uma aproximação histórica entre capoeira e Estado, diferente do século XIX. (VIEIRA, 1996; CUNHA et al, 2014).

O jogo começou a ficar pesado, intercruzando a política, o capital, o consumo e a exposição maciça da capoeira. Surgiu, então, o interesse pela formação de federações, aprovação de leis específicas de não interesse da coletividade pela capoeira e a formação de agrupamentos com fins eleitoreiros. Hoje, tanto na esfera governamental como da capoeira, há dois projetos que não se conversam no sentido de convergir, ou seja, a capoeira defendida como esporte (unificada e padronizada) e a capoeira defendida como artística/cultural e plural.

Ferreira (2016), a partir das fotos de Capoeira Angola e Capoeira Regional, faz boa análise do tipo de enunciados que esses materiais visuais propagam e influenciam no imaginário e nas disputas de poder da/na capoeira. Com base em Foucault (2008) e Vieira (1996), pode-se afirmar, inclusive, que a biopolítica a partir do Estado, conformando a ideia de corpo esportivo e a capoeira como símbolo social, foi uma força de significação da capoeira. 
Os capoeiristas também inventaram maneiras de interação socio governamental. Ao longo da existência mobilizaram, ou seja, mantiveram ativas as suas capacidades de ludibriar, fugir de situações não vantajosas, utilizando as mais diversas estratégias e, assim, construíram subjetividades outras que Ihes permitiam existir com mais dignidade. Por exemplo, no que diz respeito à atual interpretação, a não total submissão da capoeira aos códigos do esporte é o que lhe permite a pluralidade e a multiplicidade das linguagens que a constitui. Outra ação foi adequar a capoeira ao mercado do espetáculo internacional como símbolo nacional brasileiro, o que contribuiu, inclusive, para transformar ou adequar técnicas de capoeira ao que era mais agradável ao público, como saltos e movimentos espetacularizados.

\section{Considerações finais}

Conforme Campelo (1995, p. 44), o corpo é um suporte "físico-químicobiológico" que se coloca como potência na cultura que, por sua vez, possibilita a transcendência, uma forma de realizar o humano. As formas culturais de ser e compreender o corpo na capoeira constroem um texto complexo que, uma vez estudado, pode instigar o desnudar das determinações culturais que conformam os corpos, permitindo a relação crítica com as maneiras de viver, pensar e ser corpo no contexto cultural da capoeira.

Os textos descritos e analisados, vinculados a diferentes áreas do conhecimento, permitiram identificar elementos que demonstram a complexidade da relação "capoeira, corpo e tecnologia": dinâmica do corpo e mercado; dinâmica do corpo e tecnologias; dinâmica do corpo e espetáculo; dinâmica do corpo enquanto arquivo de memória; do corpo enquanto comunicante, cuja dialogia e criatividade Ihe são inerentes; corpo/capoeira e biopolítica.

Os estudos convergem no que diz respeito à compreensão de corpo enquanto totalidade e inscrição na cultura em detrimento de um entendimento biológico, mecânico do corpo e do movimento humano. Dessa maneira, a subjetivação dos indivíduos e seus grupos transita mais nos preceitos da PósModernidade do que na pseudorretidão social da Modernidade. Embora a rigidez com que muitos Mestres e grupos de capoeira querem conduzir seus grupos, a capoeira exposta na vitrine da Pós-Modernidade é consumida e também fabricada pelas pessoas no cotidiano (CERTEAU, 1998).

Dessa maneira, os estudos pontuam complexas reflexões sobre a forma como se apreende e se vive o corpo num contexto orgânico tecido por uma cultura complexa como a capoeira. A ausência de estudos sobre o tema nos cursos universitários de Educação Física talvez se deva, ainda, à pouca valorização e ou à inserção das questões socioculturais e históricas nos interesses de estudo e pesquisas na área, prevalecendo um vínculo mais efetivo com a área das Ciências Biológicas que conduzem à área da Saúde e do desempenho físico/motor.

As transformações culturais a partir das tecnologias convergem com o pensamento de MacLuhan (1969), e ajudam a refletir sobre o quanto elas ampliaram o espaço da capoeira e conformaram tanto o contexto local como o 
global numa interrelação muito dinâmica que acarreta transformações na forma como a tradição reclama a maneira mais correta de ensinar a capoeira. O autor subverte a figura do Mestre de capoeira, criando comunidades autônomas que se valem da tecnologia e da fluidez de contatos diversos com a capoeira globalizada para criarem seus repertórios de ser e viver a capoeira.

Há, por fim, divulgação dos trabalhos de capoeira pelo mundo e abertura de trabalhos aos Mestres de capoeira que aprenderam a interagir nas redes sociais e que conseguem interagir com a versatilidade das características da PósModernidade. São, portanto, novos elementos de embate com a tradição como, também, novas maneiras de conduzir o que se chama "tradição", mesmo que inventada, como ensina Hobsbwan (2012).

\section{REFERÊNCIAS}

ABREU, Caren Cristine Nobre. Ritomídia do ritualístico ao midiático: a mediatização das culturas populares de raiz de matriz africana na perspectiva da Capoeira Angola. 2012. 219f. Dissertação (Mestrado em Comunicação Social) - Pontifícia Universidade Católica de Minhas Gerais, 2012.

BAUMAN, Zygmunt. Modernidade líquida. Rio de Janeiro: Zahar, 2001.

BELFANTE, Diego Bezerra. Sou capoeira: a construção de um novo fazer-se capoeirista analisado por meio das gravações de LPS entre as décadas de 1980 a 1990. 2018. 207f. Dissertação (Mestrado em História) - Universidade Federal do Ceará, Centro de Humanidades, Programa de Pós-graduação em História, Fortaleza (CE), 2018.

CAMPELO, Cleide Riva. Caleidoscorpos: um estudo semiótico do corpo e seus códigos. São Paulo: Annablume, 1995.

CAPOEIRA, Nestor - Pequeno manual do jogador. Rio de Janeiro: Record, 2019.

CAPOEIRA, Nestor. Galo já cantou: capoeira para iniciados. Arte hoje editora, 1995.

CAPOEIRA, Nestor. Os fundamentos da malícia. $8^{a}$. Ed. Rio de Janeiro: Record, 1992.

CUNHA, Igor Márcio Corrêa Fernandes et al. Capoeira: a memória social construída por meio do corpo. Movimento, Porto Alegre, v. 20, n० 2, p. 735 a 755, abr./jun. 2014.

CERTEAU, Michel de. A invenção do cotidiano: artes de fazer. $3^{a}$. Ed. Petrópolis, RJ: Vozes, 1998. 
COSTA, Marisa Vorraber.; ANDRADE, Paula Deporte de. Na produtiva confluência entre educação e comunicação, as pedagogias culturais contemporâneas. Perspectiva. Florianópolis, v. 33, n. 2, maio/ago. 2015, pp. 843-862.

EWALD, Felipe Grüne. Memória e narrativa: Valter Benjamin, nostalgia e movência. Revista Eletrônica de Crítica e Teorias de Literaturas. Dossiê: oralidade, memória e escrita. Porto Alegre, v. 4, no 02, jul./dez. 2008.

FERREIRA, Bruno Soares. A reinvenção dos arquivos da capoeira: uma arqueologia audiovisual e biopolítica. 2016. 299f. Tese (Doutorado em Comunicação) - Universidade Federal do Rio de Janeiro, UFRJ. Rio de Janeiro, 2016.

FERREIRA, Bruno. Soares. O dispositivo da capoeira: escritas, técnicas e estéticas da existência. 2013. 155f. Dissertação (Mestrado em Educação) Universidade Federal do Rio de Janeiro, UFRJ. Rio de Janeiro, 2013.

FOUCAULT, Michel. Nascimento da biopolítica. Curso no Collège de France (1978-1979). São Paulo: Martins Fontes, 2008.

FRIGÉRIO, Alejandro. Capoeira: de arte negra a esporte branco. Revista Brasileira de Ciências Sociais, v. 4, no 10, 1989, pp. 84-98.

GIL, Antônio Carlos. Como elaborar projetos de pesquisa. 4a. Ed. São Paulo: Atlas, 2008.

GIROUX, Henry.; MCLAREN, Peter. Por uma pedagogia crítica da representação. In: SILVA, Tomaz Tadeu; MOREIRA, Antonio Flávio. (Orgs.). Territórios contestados: o currículo e os novos mapas culturais. Petrópolis, RJ: Vozes, 1995, pp. 144-158.

HOBSBWAN, Eric et al. A invenção das tradições. 2a. Ed. São Paulo: Paz e Terra, 2012.

LE BRETON, Davi. Antropologia do corpo e da modernidade. Petrópolis, RJ: Vozes, 2011.

LEMOS, André. Cibecultura: tecnologia e vida social na vida contemporânea. 4a. Ed. Porto Alegre: Sulinas, 2002.

MACLUHAN, Marshall Os meios de comunicação como extensões do homem. São Paulo: Cultrix, 1969.

MARCHESI, Mariana de Toledo. A roda em rede: as transformações culturais da capoeira nos ambientes midiáticos digitais. 2012. 411f. Dissertação 
(Mestrado em Ciências da Comunicação) - Escola de Comunicação e Artes da Universidade de São Paulo, USP. São Paulo, 2012.

NOVAES, Joana de Vilhena; Vilhena, Júlia de (Org.). O corpo que nos possui: corporeidade e suas conexões. Curitiba, PR: Appris, 2018.

PIRES, Antônio Liberac Cardoso Simoes. Movimentos da cultura afrobrasileira: a formação histórica da cultura da capoeira contemporânea. 2001. 435f. Tese (Doutorado em História) - Departamento de História do Instituto de Filosofia e Ciência Humanas da Universidade Estadual de Campinas, São Paulo. São Paulo, 2001.

ROMANOWSKI, Joana Paulin; ENS, Romilda. As pesquisas denominadas do tipo "Estado da Arte" em Educação. Revista Diálogo Educacional, Curitiba, PR. v. 6, n. 19, p. 37-50, set.-dez. 2006.

SENA, Arthur Bernardini Domene. Capoeiragem e tecnologias: possibilidades culturais. 2018. 107f. Dissertação (Mestrado em Desenvolvimento Humano e Tecnologias) - Universidade Estadual Paulista Júlio de Mesquita Filho, UNESP. Rio Claro, SP, 2018.

SILVA, Danilo de Abreu. Repassando o passado: produção e divulgação de saberes na escola de Capoeira Angola Resistência. 2013. 154f. Dissertação (Mestrado em Divulgação Científica e Cultural) - Universidade Estadual de Campinas, Unicamp. Campinas, SP, 2013.

SILVA, Luciana Maria Fernandes. O ensino da capoeira no ensino escolar: blog como apoio pedagógico. 2012. 178f. Dissertação (Mestrado em Desenvolvimento Humano e Tecnologias) - Universidade Estadual Paulista Júlio de Mesquita Filho, UNESP. Rio Claro, SP, 2012.

SILVA, Tomaz Tadeu da. Teoria cultural e educação: um vocabulário crítico. Belo Horizonte: Autêntica, 2000.

SOARES, Carlos Eugênio Líbano. A capoeira escrava e outras tradições rebeldes no Rio de Janeiro, 1808 - 1850. 2a. Ed. Campinas, SP: Ed. da Unicamp, 2004.

SOBREIRA, Vickele.; NISTA-PICCOLO, Vilma Leni.; MOREIRA, Wagner Wey. Do corpo a corporeidade: uma possibilidade educativa. Caderno de Pesquisa. São Luiz, v. 23, no 3, Set./Dez. 2016, pp. 68-77.

TAVARES, Júlio César de Tavares. Dança de guerra: arquivo e arma (elementos para uma teoria da capoeiragem e da comunicação corporal afrobrasileira). Belo Horizonte: Nandyala, 2012. 
VIEIRA, Luiz Renato. O jogo da capoeira: corpo e cultura popular no Brasil. Rio de Janeiro: Sprint, 1996.

Recebido em: 15 de abril de 2021.

Aceito em: 30 de agosto de 2021. Publicado em: 15 de dezembro de 2021. 